\title{
RELACIÓN ENTRE LAS BONIFICACIONES A LA FORESTACIÓN Y EL SISTEMA ECONÓMICO CAMPESINO
}

\author{
Gascón Castro, Aliro ${ }^{1}$ y Retamal Siefert, Pilar $^{2}$
}

\section{RESUMEN}

Las tasas de forestación están cayendo año a año el país y esto hace interesante revisar cuales son las razones para forestar de los propietarios y, específicamente en este caso, de los propietarios de Aysén.

Se realizó un estudio en la región de Aysén, con la participación de una antropóloga en proceso de titulación profesional, que tuvo como objetivo conocer las experiencias de los pobladores locales con los incentivos de fomento estatales para la forestación y en relación a las plantaciones de especies arbóreas y sus sistemas económicos. Este estudio se centró en la Comuna de Coyhaique de la Región de Aysén.

Las hipótesis de trabajo apuntan a si el sistema económico es determinante en la toma de decisiones para realizar una forestación o si la forestación se encuentra condicionada por rasgos culturales y económicos, externos e internos, del sistema económico campesino.

La metodología para la recolección de datos fue la recolección de elementos cualitativos, mediante entrevistas semiestructuradas, herramienta que recaba el grueso de la información para el trabajo, registros etnográficos y revisión bibliográfica.

Como resultado de este estudio, se aprecia que los objetivos planteados por los campesinos giran en torno a un mejoramiento del predio, con la convicción de un mejoramiento del medio, pero siempre teniendo en cuenta que hay necesidades inmediatas que son mucho más valiosas y en pocas ocasiones se busca una maximización económica.

Los usos que se da a estas plantaciones se encuentran siempre ligados a los objetivos que poseen las personas. Estos se fundamentan principalmente en la actividad económica identificada por la gente como primordial a lo largo de su historia, que es la ganadería.

La satisfacción de requerimientos domésticos es fundamental para el poblador. Es decir, las plantaciones son orientadas hacia la recuperación de suelos, que en la región es un objetivo fundamental. También se deben considerar elementos tales como el forraje y el abrigo para los animales, en términos de constituir un ahorro en insumos y gastos.

Se ratifica la hipótesis de la forestación asociada preferentemente a rasgos culturales, aunque también a aspectos económicos y ambientales, porque en primer término en muchos

1 Ing. Forestal. Magíster en Desarrollo Rural. Corporación Nacional Forestal. Aysén, Chile. aliro.gascon@conaf.cl 2 Antropóloga (E). Universidad Católica de Temuco. pilar.retamalsiefert@gmail.com 
campesinos el eje es lo ambiental, lo secundario son los incentivos del Estado. Este punto tiene que ver con los tipos de racionalidad que se establecen en los campesinos; a largo plazo y una a corto plazo, condicionada por la naturaleza como capital.

Palabras claves: Forestación campesina, incentivos, racionalidad económica campesina.

\section{SUMMARY}

The year to year afforestation rates falling turns interesting a review on the reasons to establish forest plantations, particularly in this case in the Aysen region.

With the participation of a pre graduated anthropologist, a study was carried out to know the local land owners experience on the State incentives for afforestation and the relationship of planted forest to their economical systems. The study was focused on the Coyhaique commune in the Aysen region.

Working hypothesis were if economical system is a deciding factor to forest or the afforestation is conditioned by cultural an economic subjects, internal or external to their economic system.

Methodology to collect qualitative data was through semi structured interviews, obtaining most of the information for the work, ethnographic records and bibliographic revision.

Results show that main land owner objectives are related to farm improvement, feeling that as an environmental improvement also, but always taking in due account immediate and more valuable needs. In a few cases to maximize economic results is the goal.

Planted forest use is always linked to the main land owner objective, consisting on ranching and considered by the peasants as their paramount historical economic activity.

Domestic needs satisfaction is a crucial matter for peasants. Soil recovering is a central objective in the region and planted forest use is focused on that. Also are considered functions as fodder production and cattle shelter, mainly in terms of inputs and other costs saving.

Hypothesis is ratified in terms of afforestation decisions associated mainly to cultural peasant features, but considering also economical and environmental matters, because many farmers have the environment as a key point. Governmental incentives are in a secondary position. Peasants in the region have both, a long term and a short term rationality, and nature is perceived as a capital.

Key words: Farmer afforestation, forest incentives, farmer economic system. 


\section{INTRODUCCIÓN}

Para fomentar la reactivación de la forestación, se debe conocer las motivaciones que tienen los usuarios, sobre todo los campesinos, al momento de tomar de decisión de incorporar especies forestales a sus suelos.

Con el fin de intentar encontrar posibles respuestas a las causas de la caída de las tasas de forestación en los últimos 3 ó 4 años, el Departamento Forestal de la Corporación Nacional Forestal (CONAF) de la Región de Aysén se planteó revisar las razones que tienen los campesinos para forestar sus predios en la región de Aysén.

Algunos profesionales de la Corporación, en particular asociados al fomento y desarrollo forestal, suponían que la explicación principal estaba en los incentivos estatales a la forestación, es decir en el diferencial positivo que genera la bonificación que entrega el Estado.

Sin embargo, es necesario probar esta tesis, dada su connotación negativa respecto de un interés cortoplacista de los pequeños y medianos propietarios, sin importar otras consideraciones como las ambientales y las económicas a largo plazo en relación a la capitalización del predio.

CONAF en conjunto con la carrera de Antropología de la Universidad Católica de Temuco decidió hacer un trabajo en el tema, que sirviera además como práctica profesional y generara posteriormente una Tesis de Grado. El presente trabajo se entrega los primeros resultados obtenidos.

El trabajo se funda es dos hipótesis relacionadas:

- El sistema económico determinante en la toma de decisiones al momento de decidir realizar o no una forestación.

- La forestación se encuentra condicionada por rasgos culturales y económicos, externos e internos del sistema económico campesino.

\section{OBJETIVOS}

\section{Objetivo General}

Conocer las experiencias de los pobladores locales en el programa de bonificación forestal en relación a las plantaciones de especies exóticas y sus sistemas económicos en la comuna de Coyhaique.

\section{Objetivos Específicos}

Identificar las principales actividades económicas presentes en los predios de los pobladores locales, mediante la significación a sus recursos naturales. 
Conocer las experiencias de los pobladores locales con el programa de bonificación forestal en relación a las plantaciones de especies exóticas.

\section{METODOLOGÍA}

Todo proyecto en el mundo rural pretende solucionar o mejorar alguna condición propia de la comunidad en la que estará inserto. Las intervenciones de estos proyectos causan algún tipo de impacto, los que pueden ser positivos, negativos o nulos, dependiendo de quién los mida, la metodología que use para ello y la visión que se tenga del problema (Gascón, 2010).

En Chile y en particular en el mundo rural, no es común encontrar proyectos que midan impactos y mucho menos que éstos sean formulados por la población sujeto de la intervención (Gascón, 2010), por tanto conocer mediante metodologías de las ciencias sociales la percepción que tienen los campesinos, usuarios de los programas de fomento vinculados a las plantaciones, es de vital importancia para que estos programas se mantengan en el tiempo logrando impactos positivos desde la mirada de los usuarios.

El tema aquí abordado desde las ciencias sociales y en particular desde la antropología, tendrá la modalidad de ser de carácter exploratorio cualitativo. Entendiendo que el investigador social se sitúa en un determinado orden social, intentando comprender a otros sujetos (actores) que se encuentran en el mismo orden. Para ello el analista social utiliza sus significaciones disciplinarias para encontrar sentido a lo estimado como real. Por lo dicho se debe tener en cuenta que se establece una relación sujeto a sujeto, donde el sujeto investigador es el intérprete de otros, estimando su disciplina, teniendo presente sus determinaciones. Por lo tanto se trata de una creación de un investigador sobre la representación de actores sociales que desde sus significados interpreta.

\section{Análisis Conceptual}

\section{- Concepto de Campesino}

Desde diversas concepciones, distintos autores analizan a los sujetos llamados "campesinos", considerando elementos socio-culturales, políticos y económicos.

Wolf (1982) plantea que "los campesinos son esos amplios sectores de la humanidad que se encuentran entre la tribu primitiva y la sociedad industrial. Son importantes desde el punto de vista histórico a causa de que la sociedad industrial ha sido edificada sobre las ruinas de la sociedad campesina".

Además Wolf (1982) plantea que “...los campesinos, sin embargo, son cultivadores cuyos excedentes son transferidos a grupos dominantes que los utilizan en dos sentidos; para asegurar su propios estándares de vida y para distribuir al resto, a grupos de la sociedad que no cultivan, pero que deben ser alimentados a cambio de sus bienes específicos y servicios." 
Se distinguen tres características esenciales para la definición de campesinado

- El campesinado es un productor agrícola.

- Es propietario de la tierra y controla efectivamente el terreno que cultiva.

- Cultiva para su propia subsistencia, pues aunque venda parte de sus cosechas lo hace para cubrir sus necesidades cotidianas y para mantener un status establecido.

La unidad campesina es parte de un conjunto más amplio de unidades de producción que en algo difieren de las más típicas unidades capitalistas de la economía global y tienden a estar en "flujo hacia" o "resistiendo el flujo hacia" otro tipo de unidades productivas que en algo se les asemejan (Murmis, 1980). Concluye la fuente señalando que la unidad campesina o con rasgos campesinos es un subconjunto de la categoría pequeños productores.

"Los campesinos son definitivamente rurales, aunque viven relacionados con los mercados urbanos. Forman un sector de clase de una población más amplia que normalmente contiene centros urbanos y a veces capitales con carácter de metrópoli. Constituyen saciedades parciales con una cultura parcial, carecen de aislamiento, autonomía política, autosuficiencia de la población rural, y sus unidades locales retienen mucho de su identidad, integración y apego al suelo y cultivo" (Kroeber, 1948).

El funcionamiento y la organización de la economía campesina no se basan en los postulados de una economía capitalista, este se caracteriza por su carácter familiar y de subsistencia por tanto es una economía familiar, donde su organización, unidad de producción es familiar y no consiste en acumular. La obtención de ganancia puede existir, pero no como un objetivo central. Del anterior resumen se desprende que "toda su organización está determinada por la composición familiar del campesinado, el número de miembros que integra, su coordinación, sus demandas de consumo y el número de trabajadores con los cuales cuenta" (Chayanov, 1931. Citado por Wolf, 1982)

De acuerdo a esto, el beneficio en la economía campesina difiere al de la economía capitalista. Así se entiende que el trabajo de los campesinos no se puede expresar en rubros, ya que la unidad es la familia, no hay un salario o retribución fija, sino más bien sujeto al producto total conseguido con posterioridad, ya sea en las ventas de madera, de animales o productos que reembolsan de los bosques. Por tanto el producto del campesino se sustrae del consumo. Está condicionando el producto anual o por temporadas que consigan para valerse de herramientas para una próxima temporada.

Chayanov 1931 (Citado por Wolf, 1982) considera entonces que el objetivo principal de la economía campesina es "la satisfacción del presupuesto anual del consumo de la familia, su mayor interés no radica en la remuneración de la unidad de trabajo (trabajo diario), si no en la del trabajo de todo el año".

Calva (1988) define al sujeto campesino como "el poseedor de una porción de 
tierra que explota por su cuenta, con su propio trabajo manual, como ocupación exclusiva o principal, apropiándose de primera mano, en todo o en parte, los frutos obtenidos y satisfaciendo con éstos, directamente o mediante su cargo, las necesidades familiares". Esta definición sugiere varios aspectos, el primero de ellos es la relación que mantiene el sujeto con la tierra. De ello se desprenden los asalariados rurales, pero un capitalista y un rentista también poseen tierra. Por tanto este criterio, por sí solo, es insuficiente para identificar a los campesinos. Si la tierra (siempre según la definición de Calva, 1988) es explotada por parte de su poseedor, deja fuera al rentista o arrendatario. Al ser trabajada por su propio trabajo manual deja fuera al capitalista, pues este contrata trabajadores externos a la explotación remunerados mediante un salario. La condición de ocupación exclusiva o principal margina a los que poseyendo los atributos enunciados precedentemente, obtienen la mayor parte de sus ingresos de otras actividades no vinculadas al recurso suelo. El hecho de apropiarse de primera mano de los frutos obtenidos, da a entender el control del destino del producto que ejerce el productor, de esta manera, dependiendo de la relación social de producción, quedan fuera los productores vinculados a la agroindustria.

En síntesis, se puede dejar fuera de la definición de campesino a productores agrícolas que tengan alguna de las siguientes características: Capitalista o empresario agrícola, rentista, productor agroindustrial y obrero agrícola.

Figueroa (1998) ha planteado, respecto al sistema de producción campesino, que la mano de obra familiar es la principal fuente de oferta laboral, la agricultura es la principal fuente de ingresos y la productividad es tan baja, que no hay capacidad de generación de excedentes económicos. Según Shanner (1982), el comportamiento productivo de la unidad campesina manifiesta una racionalidad particular que le otorga al campesino características duales entre producción y consumo, asegurando sobre todo la estabilidad y sobrevivencia de la familia y de su predio.

Es importante tener en cuenta que la transformación se produce tanto hacia abajo como hacia arriba (Wolf 1978, citado por Murmis, 1980). El cambio hacia arriba, "de campesino a agricultor", eliminaría las relaciones de dependencia con el campo y afirma a la vez al capitalismo. Dentro de la mirada capitalista, el cambio hacia abajo es de campesino a obrero agrícola. Por otro lado, este autor ha identificado tres fases en el proceso. La primera la denomina diferenciación y la define como el estado en el cual los rasgos campesinos aún son dominantes. La segunda fase, llamada descomposición, se caracteriza por un estado en el cual los rasgos campesinos son secundarios al momento de definir la condición de la unidad doméstica. Finalmente, la tercera fase, denominada descampesinización, se emplea para designar a aquellas unidades que una vez fueron campesinas y que ahora se encuentran en otra situación

Al interior de la economía, para los que asumen una opción formalista de la producción campesina, el asunto se reduce a aplicar las categorías desarrolladas, particularmente, por la corriente marginalista a la producción campesina y su situación, habitualmente, es explicada como resultado de una carencia (educación, tecnología, etc.) o resistencia por parte de los integrantes de las unidades campesinas a adoptar conductas o comportamientos que sean compatibles con los "principios" de la microeconomía (Bahamondes, 2000). 
En Cuadro $\mathrm{N}^{\circ} 1$, se describen las diferencias entre la agricultura campesina y la agricultura empresarial.

\section{Cuadro $\mathrm{N}^{\circ} 1$ \\ DIFERENCIAS ENTRE AGRICULTURA CAMPESINA Y AGRICULTURA EMPRESARIAL}

\begin{tabular}{|c|c|c|}
\hline ATRIBUTOS & AGRICULTURA CAMPESINA & $\begin{array}{l}\text { AGRICULTURA } \\
\text { EMPRESARIAL }\end{array}$ \\
\hline $\begin{array}{l}\text { Objetivo de la } \\
\text { producción }\end{array}$ & $\begin{array}{l}\text { Reproducción de la familia y de la unidad de } \\
\text { producción }\end{array}$ & $\begin{array}{l}\text { Maximizar la tasa de } \\
\text { ganancia y la acumulación } \\
\text { de capital. }\end{array}$ \\
\hline $\begin{array}{l}\text { Origen de la fuerza de } \\
\text { trabajo }\end{array}$ & $\begin{array}{l}\text { Fundamentalmente familiar y, en ocasiones, } \\
\text { intercambio recíproco con otras unidades; } \\
\text { excepcionalmente asalariada en cantidades } \\
\text { marginales }\end{array}$ & Asalariada \\
\hline $\begin{array}{l}\text { Compromiso laboral } \\
\text { del jefe con la mano } \\
\text { de obra }\end{array}$ & Absoluto & $\begin{array}{l}\text { Inexistente, salvo por } \\
\text { obligación legal }\end{array}$ \\
\hline Tecnologías & $\begin{array}{l}\text { Alta densidad de mano de obra, baja } \\
\text { densidad de capital y de insumos } \\
\text { comprados por jornada de trabajo. }\end{array}$ & $\begin{array}{l}\text { Mayor densidad de } \\
\text { capital por activo y mayor } \\
\text { proporción de insumos } \\
\text { comprados en el valor del } \\
\text { producto final }\end{array}$ \\
\hline $\begin{array}{l}\text { Destino del producto y } \\
\text { origen de los insumos }\end{array}$ & Parcialmente mercantil & Mercantil \\
\hline $\begin{array}{l}\text { Criterio de } \\
\text { intensificación del } \\
\text { trabajo }\end{array}$ & $\begin{array}{l}\text { Máximo producto total, aún a costa del } \\
\text { descenso del producto medio. Límite: } \\
\text { producto marginal cero }\end{array}$ & $\begin{array}{l}\text { Productividad marginal > } \\
\text { salario }\end{array}$ \\
\hline Riesgo e incertidumbre & $\begin{array}{l}\text { Evasión no probabilística: "algoritmo de } \\
\text { sobrevivencia" }\end{array}$ & $\begin{array}{l}\text { Internalización } \\
\text { probabilística buscando } \\
\text { tasas de ganancia } \\
\text { proporcionales al riesgo }\end{array}$ \\
\hline $\begin{array}{l}\text { Carácter de la fuerza } \\
\text { de trabajo }\end{array}$ & $\begin{array}{l}\text { Fuerza valorizada de trabajo intransferible o } \\
\text { marginal }\end{array}$ & $\begin{array}{l}\text { Sólo emplea fuerza de } \\
\text { trabajo transferible en } \\
\text { función de calificación }\end{array}$ \\
\hline $\begin{array}{l}\text { Componentes del } \\
\text { ingreso o producto neto }\end{array}$ & $\begin{array}{l}\text { Producto o ingreso familiar indivisibles y } \\
\text { realizados parcialmente en especies }\end{array}$ & $\begin{array}{l}\text { Salario, renta y ganancias } \\
\text { exclusivamente } \\
\text { pecuniarias. }\end{array}$ \\
\hline
\end{tabular}

(Fuente: Schejtman, 1982)

\section{- Antecedentes de las Familias Campesinas y su Propiedad en la Comuna de Coyhaique}

Según Saavedra (2001), en la comuna de Coyhaique, el $18 \%$ de los predios tiene aptitud netamente forestal y por ello se les utiliza sólo como explotaciones forestales, especialmente en la producción de leña; el 58 \% participa con lo forestal y lo ganadero; y el $24 \%$ restante sólo ganadería. Un margen muy reducido complementa su actividad económica con agricultura, turismo y otras actividades. 
Por tanto, sobre el $75 \%$ de los predios utilizan el bosque, preferentemente para el consumo y venta de leña, como también para la producción de trozos, madera aserrada, postes y varas.

En el Cuadro $\mathrm{N}^{\circ} 2$ se describen algunas características generales de los habitantes propietarios de explotaciones rurales de la comuna de Coyhaique (Saavedra, 2001).

\section{Cuadro $\mathrm{N}^{\circ} 2$}

CARACTERÍSTICAS DE LOS HABITANTES RURALES DE LA COMUNA DE COYHAIQUE

\begin{tabular}{|l|l|}
\hline CONCEPTO & CARACTERÍSTICAS \\
\hline Estructura familiar & Hogares pequeños y/o familias extensas \\
\hline Edad & Edad promedio propietarios, 62 años \\
\hline Escolaridad propietarios & 2,6 años. (bajos ingresos = baja escolaridad) \\
\hline Socio - economía & Estrato de pobreza \\
\hline Actividad productiva & $1^{\circ}$ Ganadería, $2^{\circ}$ Actividad de bosque. Superficie forestal promedio: 62,8 ha. \\
\hline Tamaño medio propiedad & 130 ha. \\
\hline Fuerza de trabajo & Familiar, uno a tres trabajadores. Edad media: 46,5 años. \\
\hline
\end{tabular}

FUENTE: Saavedra (2001)

\section{- Localización del Estudio.}

Esta investigación se situó en Villa Ortega, El Richard, Emperador Guillermo, Rodeo los Palos, Lago Pollux y Lago Frío, todas localidades pertenecientes a la comuna de Coyhaique y provincia homónima.

\section{- Muestra}

La muestra utilizada sirve para conocer posiciones discursivas diferentes, constituyéndose respecto a un problema social determinado. Es decir, conocer hablas particulares del ámbito social, siendo netamente cualitativo. Por lo tanto, teóricamente el universo a considerar estará determinado por lo social y está situado en cada parte porque se encuentra en el todo. Esto indica que lo importante son las particularidades y la realidad social tomando en cuenta su heterogeneidad. Ahora bien, los criterios seleccionadores se rigen por las relaciones que las personas que se eligen puedan reproducir, permitiendo conocer discursos que se elaboran en torno al tema propuesto. De este modo la representatividad esta otorgada por la legitimación de la saturación o agotamiento del tema establecido. Por lo tanto, lo que se quiere ver es qué recursos se encuentran manejando en la actualidad que influyen en sistemas de reproducción material y que condicionan decisiones de realizar plantaciones.

La muestra entonces se determinó en base a personas que hayan forestado entre 
los años 1998 al 2006. Se estima entrevistar al 20\% de las personas con la finalidad de poder conocer los discursos existentes en torno a la forestación y a identificar los recursos naturales que se manejan.

\section{- Instrumentos de Recolección de Datos}

Para la recolección de datos se han usado técnicas cualitativas de entrevistas semi-estructuradas, herramienta que podrá recabar el grueso de la información para esta investigación, registros etnográficos y revisión bibliográfica.

\section{Revisión Bibliográfica}

Se utilizan fuentes biográficas como documentos, libros, artículos, para abordar los temas aquí tratados, tales como plantaciones, sistemas de reproducción material, historia local, y otros antecedentes, ya sean estos demográficos, climáticos, sociopolíticos u otros, y fuentes secundarias referidas al Decreto Ley 701, programa de bonificación forestal, antecedentes de la Corporación Nacional Forestal y otros.

\section{Registros Etnográficos}

Los registros etnográficos giran en torno a identificar a los actores locales, que participan en la realización de plantaciones, para realizar un primer acercamiento empírico de conocimiento de sus recursos naturales y actividades económicas. En segunda instancia poder identificar y describir formas de organizarse económicamente que proporcionan las decisiones de realizar forestaciones en los predios.

Los registros etnográficos apuntan a poder recoger observaciones de los terrenos realizados, las cuales son diarias y en base a los objetivos trazados en el diseño efectuado. Las observaciones son hechas en terreno. Esto quiere decir que el investigador social estará describiendo lo que ve y analizando teóricamente (interpretando) esas observaciones del fenómeno social investigado.

Los pasos a seguir en los registros etnográficos son los siguientes:

Notas de campo: Apuntes de las observaciones tomadas en terreno, realizadas por el etnógrafo, tomando en cuenta las diversas prácticas que se realicen en el día, estas serán teorizadas con posterioridad.

Cuadernos de campo: Constituye la sistematización de las notas de campo, formalizándolas a partir de cada terreno realizado.

Diario de campo: Es el conjunto de cuadernos de campo realizando un diario por sector visitado.

Loimportante de los registrosetnográficosesquese puedan plasmarlas observaciones 
realizadas durante el día para luego ser interpretadas desde la Antropología.

\section{Entrevistas Semi-Estructuradas}

Las entrevistas realizadas así como los registros etnográficos son el fuerte de información investigativa. Así, las entrevistas dan a conocer las opiniones de la población sobre un determinado fenómeno social. Por lo tanto, las preguntas son formuladas de acuerdo a los objetivos especificados y al flujo de la conversación.

Las entrevistas son puestas bajo análisis, realizado bajo categorizaciones, codificaciones y sistematizaciones representativas de los análisis.

\section{Cuadro $\mathrm{N}^{\circ} 3$ \\ NÚMERO DE USUARIOS DIRECTOS ENTREVISTADOS POR RANGO DE SUPERFICIE}

\begin{tabular}{|c|c|c|c|}
\hline & 1-50 ha & 51-99 ha & Más de 100 ha \\
\hline $\begin{array}{c}\text { Entrevistas a } \\
\text { usuarios }\end{array}$ & 11 & 1 & 1 \\
\hline
\end{tabular}

\section{RESULTADOS}

La perspicacia social es fundamental para elaborar y ejecutar programas forestales, ya que se requiere de una participación local de pobladores que se ven afectados o beneficiados para lograr prosperidad en las áreas rurales y una optima administración de recursos naturales. Para ello un análisis antropológico de estos actores y protagonistas sociales en conjunto proporciona herramientas fundamentales para el funcionamiento de programas, por la razón simple de adentrarse e interesarse, ya sea en "sus sistemas de tenencia de tierra, modelos de diferenciación rural, formas locales de organización del trabajo, conocimiento de necesidades, y comprensión de sistemas de reproducción material, o en términos de simples sistemas económicos" (Cernea, 1996).

Ahora bien, se debe tener en cuenta que en las poblaciones rurales la extracción de árboles es uno de los mecanismos primordiales de la economía campesina, ya sea para combustible, venta, u otros fines, por lo que la extracción de estos recursos forestales se vuelve tan importante como lo es el trabajo, la comida y eventos sociales de convivencia. Esta relación con los árboles (productos forestales) se vuelve un ingreso hacia la economía en determinadas estaciones del año, apoyando otras actividades económicas subyacentes, esto determinado por el contexto y el territorio en el cual se viva, ya que poseerá particularidades partiendo de las condiciones climáticas.

Entendiendo que en poblaciones rurales la extracción de árboles es un ingreso y a la vez símbolo de encuentros familiares, sociales de convivencia, proporcionando calor (combustible ), es que se debe tener en cuenta que los medios hoy en día de autorización para obtener madera y otros productos están siendo más problemáticos y burocráticos, 
por lo que se incita con mayor fuerza a talas ilegales y a la vez a la desconfianza entre pobladores y organismos del Estado, más específicamente con los funcionarios, llegando a cuestionar fuertemente procedimientos de índole económica y política.

Esto radica en que se debe dejar en el ámbito del desarrollo problematizar desde fuera toda la vida de pobladores, campesinos, esto se refiere a hacer suposiciones de cómo deberían funcionar acorde a los sistemas económicos imperantes, o cuestionarlos por sus formas de entender el bosque, y de vivir. Es hora que instituciones y profesionales establezcan una participación directa desde dentro con los actores sociales en los proyectos, primero empezando por conocer sus organizaciones sociales y prácticas tradicionales, que en este informe corresponde a la plantación de árboles, llegando a lograr una administración y conciencia de plantar árboles con el fin de lograr la conservación tan esperada, teniendo en cuenta que son los ingresos de sobrevivencia de los pobladores.

Dentro del análisis realizado tras la categorización y codificaciones se puede decir que los principales objetivos y finalidades de la realización de las plantaciones por parte de los pobladores son las que se comenta a continuación.

Principalmente los objetivos giran en torno a un mejoramiento del predio con la convicción de un mejoramiento del medio, pero siempre teniendo en cuenta que hay necesidades inmediatas que son mucho más valiosas y en pocas ocasiones se busca una maximización económica. Entre las motivaciones se recalca las siguientes:

Plantar en terrenos erosionados

Por el incentivo económico estatal

Mejoramiento del paisaje

Cortinas cortavientos

Para el brote del pasto

Para recomponer o hacer cercos

Para generaciones futuras

Los usos que se les dan a estas plantaciones se encuentran siempre ligados a los objetivos que poseen las personas. Estos se fundamentan principalmente en la actividad económica identificada por la gente como primordial a lo largo de su historia, que es la ganadería. Por lo tanto, se refiere a la ganadería como un elemento tradicional perdurable que se encuentra condicionando su actuar ideológico y simbólico en la cotidianidad. Entre los usos más destacables se encuentran:

Para colocar animales 
Para uso maderero

Para leña (combustible)

Para construcción

Forraje para los animales cuando escasea.

Las finalidades, lo que se espera de estas plantaciones:

Abrigo para los animales en invierno

Darle utilidad a terrenos sin uso

Darle sombra a animales en verano

Ampliar pradera.

La satisfacción de requerimientos domésticos es fundamental para el poblador. Con esto se quiere decir que si las plantaciones son orientadas hacia la recuperación de suelos, que en esta región es el eje fundamental, también se deben considerar elementos tales como el forraje, el abrigo para los animales con el motivo de ser beneficioso y en convertirse en un ahorro en los gastos.

Otro punto importante son las experiencias en plantaciones, estas se ven desde dos perspectivas, primero experiencias que han sido buenas, ya que han respondido a los objetivos propuestos por los pobladores (antes mencionados) y se han beneficiado en el ámbito del incentivo, considerando esto como una base para implementar la plantación. La otra perspectiva ha sido mala, ya que se ha realizado plantaciones en lugares no aptos para el prendimiento de los pinos y se han visto envueltos en grandes deudas que solo el vender su capital puede recuperar su tranquilidad monetaria.

Lo anterior obliga a considerar dos tipos de pobladores rurales dependiendo de sus objetivos en plantaciones:

Personas interesadas en recuperar su campo y forestar con la idea que no se produzca más erosión.

Personas para las que la forestación es un tema de bonificación o negocio, no importándole plantar en terrenos que usaba para la ganadería. 


\section{Cuadro $\mathrm{N}^{\circ} 4$ \\ RACIONALIDADES IDENTIFICADAS EN LOS CAMPESINOS}

\begin{tabular}{|l|l|}
\hline $\begin{array}{l}\text { 1. } \\
\text { Recuperación de campo } \\
\text { para frenar erosión }\end{array}$ & $\begin{array}{l}\text { Racionalidad a largo plazo que implica concepción de técnicas y } \\
\text { procedimientos productivos para una mejor conservación del suelo. } \\
\text { Por lo tanto hay una sostenibilidad }\end{array}$ \\
\hline $\begin{array}{l}\text { 2. El medio natural visto } \\
\text { como capital }\end{array}$ & $\begin{array}{l}\text { Racionalidad a corto plazo, ya que predominan dominios económicos } \\
\text { produciendo una insostenibilidad }\end{array}$ \\
\hline
\end{tabular}

Por lo tanto, es fundamental poder comprender los cálculos desde el punto de vista del poblador rural campesino, ya que se deben considerar intereses particulares para poder planificar óptimamente a quien se dirigen las plantaciones. No obstante, no hay que olvidar que lo representado en el cuadro se pudiese ver combinado en la realidad social, produciendo prácticas de sostenibilidad e insostenibilidad. También hay que tener en cuenta que las prácticas de sostenibilidad pueden tener como consecuencia una sustentabilidad en el tiempo, aun no dimensionándolo.

Las experiencias personales de la gente son fundamentales para lograr un optimo desarrollo de las plantaciones, ya que muchas veces estas poseen métodos diferentes en los procedimientos y deben ser escuchados en primera instancia para llegar a un entendimiento en cómo quieren ellos que se realice, se está hablando de una administración forestal para la realización de la plantación. Siempre los pobladores van a tener conocimiento en lo que respecta al crecimiento de los árboles, a la distancias, al trasplante de plantas, y otros aspectos, y este es el eje central para que exista un sostenimiento de una plantación y ocasionar una participación inclusiva, directa, interesante para ellos, integrando prácticas de plantación local.

Las comunidades, poseen una historia en un contexto particular, con determinadas características climáticas y ecológicas, estableciendo sistemas de cultivo, ya sean estos de árboles, de hortalizas, u otros. En consecuencia no se debe ignorar su conocimiento.

\section{Cuadro $\mathrm{N}^{\circ} 5$}

INCENTIVOS ECONÔMICOS E INCENTIVOS VALÓRICO - SIMBÓLICOS

\begin{tabular}{|c|c|}
\hline Incentivo económico & $\begin{array}{l}\text { Implementación de plantación } \\
\text { - } \quad \text { Problemas cuando hay escasez de fondos gubernamentales cuando no hay prendimiento } \\
\text { Perdida de objetivos primordiales (dependiendo de las } \\
\text { particularidades). }\end{array}$ \\
\hline Incentivo valórico - simbólico & $\begin{array}{l}\text { Necesidades locales } \\
\text { Vinculación con otros proyectos por ejemplo: de riego, } \\
\text { infraestructura, etc. } \\
\text { Refuerza la comprensión social de la cultura local. } \\
\text { Identifica nuevas opciones para plantaciones } \\
\text { - Reduce riesgos en ámbito de proporcionar forraje y pasto. } \\
\text { Contemplar a la familia entera en el trabajo de plantación } \\
\text { como responsables. }\end{array}$ \\
\hline
\end{tabular}


El tema de las bonificaciones o incentivos es fundamental al referirse a las plantaciones, especialmente cuando se percibe que para que exista interés tiene que ser antepuesto este beneficio, pero la duda es si hay otras formas de concebir o de presentar un incentivo. Para ello es fundamental poder conocer estructuras organizativas incentivantes en territorios socioculturales, sin embargo, es la localidad a la cual se debe recurrir, considerando que en ella se visualizan acciones, sean estas comunitarias o individuales, configurando manifestaciones de necesidades, potenciales gestionantes, valores. Esto se traducirá en que los nuevos incentivos puedan contemplar el reconocimiento de la autonomía en decisiones, ya sean estas administrativas, seguridad en cuanto a la tenencia de los árboles, intereses netamente campesinos (evaluar necesidades), vinculación con otros proyectos que ayuden al predio, por ejemplo de riego, infraestructura, cultivos de nuevos árboles para la siembra, que no sean pinos y que los identifiquen como pobladores.

Para poder insertar este tipo de modificaciones en los incentivos es necesario que se reestructuren otras cosas, por ejemplo que las plantas no se cobren, o que se mantenga un vivero para estos fines. Por otra parte se encuentran las limitaciones y beneficios que les han entregado las plantaciones a los pobladores rurales entrevistados.

\section{Cuadro $\mathrm{N}^{\circ} 6$ \\ LIMITACIONES Y CONSECUENCIAS DE LAS PLANTACIONES}

\begin{tabular}{|l|l|}
\hline \multicolumn{1}{|c|}{ LIMITACIONES } & \multicolumn{1}{c|}{ CONSECUENCIAS } \\
\hline $\begin{array}{l}\text { Amontonamiento del pino por falta de raleo } \\
\text { y poda }\end{array}$ & $\begin{array}{l}\text { No proporciona pasto para los animales } \\
\text { Cubre de pino praderas que son aptas para el } \\
\text { Alzamiento de semillas }\end{array}$ \\
ganado \\
Mantaciones en meses incorrectos & Mal emprendimiento y no existencia de \\
Daños al ganado plantas & Mal prendicación \\
Clima & Mal parir de vacas (por especie determinada de \\
& pino). \\
\hline
\end{tabular}

\section{Cuadro $N^{\circ} 7$}

\section{BENEFICIOS Y CONSECUENCIAS DE LAS PLANTACIONES}

\begin{tabular}{|l|l|}
\hline \multicolumn{1}{|c|}{ BENEFICIOS } & \multicolumn{1}{c|}{ CONSECUENCIAS } \\
\hline Formación de pasto en cerros pelados & Forraje para los animales \\
Bonificación por terreno inútil & Ingreso, apoyo a economía campesina \\
Composición de terreno & Abrigo para los animales \\
\hline
\end{tabular}

\section{DISCUSIÓN}

Las limitaciones y beneficios son síntomas de cómo los pobladores viven el riesgo. Se debe tomar en cuenta que si se ha plantado un árbol en determinado año, este va a ser 
más valioso, que considerarlo para 20 años mas allá, por la simple razón de considerar cosas más inmediatas como por ejemplo el pasto que saldrá al cabo de un tiempo sirviendo como forraje para sus actividad primordial tradicional que es el ganado. Se debe por tanto considerar para incentivar plantación, las necesidades locales.

Algunos comentarios extraídos de las entrevistas, que enriquecen la discusión:

"Estuve encargado de 70 hombres como administrador para forestar, y forestamos harto. En ese tiempo se plantaba a metro la planta, $1 \times 2 \mathrm{~m}$, ahora se ha ido modernizando, se planta a 2 × 4 y 4 × $4 \mathrm{~m}$, ahora hay muchas plantaciones que se están raleando, le estoy hablando del 77 ".

“...yo le decía que uno tiene su experiencia de ¿cómo se crecen los árboles? ¿Cómo se crece mejor?, pero los ingenieros lo que han hecho no está bien enseñado, en su estudio, pero el campesino tiene su experiencia de que ese árbol no va hacer bonito, se tuercen porque están juntos y se empiezan a raspar".

"No sabía, cuando el vecino, lo hizo, ahí recién se enteró, el hizo plan de manejo, un raleo, porque lo vino a buscar el vecino para ayudarlo a marcar los pinos y él me marcó los pinos, ahí aprendí y supe. Empecé a podar esos pinos."

Adentrarse en esto conlleva a ver el territorio, pero territorio considerado desde el ámbito humano, donde se permita ver como la gente trabaja, se relaciona con su medio y con otras personas y reconocer este como un lugar activo de participación por parte de pobladores, no expectantes a lo que pueda suceder, sino mas bien actuantes de sus propios problemas y necesidades, las cuales reaccionan ante situaciones de una forma colectiva.

El tema de las bonificaciones o incentivos es fundamental, no hay interés por plantar sin estos beneficios y se abre la interrogante sobre si hay otra forma de concebir o presentar los incentivos. Es muy importante para esto conocer estructuras organizativas incentivantes en territorios socioculturales, sin embargo se debe revisar la localidad, en ella se visualizan acciones comunitarias e individuales, y se configuran manifestaciones de necesidades, potenciales gestionantes, valores. En este contexto, los nuevos incentivos pueden contemplar el reconocimiento de la autonomía en decisiones, seguridad en cuanto a la tenencia de los árboles, intereses netamente campesinos, vinculación con otros proyectos que ayuden al predio, cultivos de nuevas especies para plantaciones que los identifiquen como pobladores, y otros aspectos.

Las experiencias de las personas en torno a sus interpretaciones son de gran valor antropológico para poder comprender los sistemas de reproducción material de los campesinos, ya que esto proporcionará un entendimiento de cuáles son las necesidades, las que hay que exponer al momento de elaborar un programa, sea este de bonificación o de forestación. Entender que las necesidades campesinas son de primer orden y deben considerarse como tales en los incentivos, en la forma de realizar plantaciones, incorporando el pensamiento local de los campesinos y encaminándose hacia una participación en todos sus términos. 
No obstante, esto sólo no cubrirá la totalidad del problema, hay que considerar que la hegemonía de la economía capitalista neoliberal provoca que en los rincones más remotos del mundo el sistema afecte a economías locales, repercutiendo en formas de organización, formas de vida y en formas de sustentarse económicamente. "Entendiendo que todo lo que consideramos como económico se occidentalice y se conceptualice como una visión de la hegemonía del capitalismo y de la subordinación de distintos sistemas económicos a él" (Comas, 1996).

El problema tiene una dimensión subjetiva, arraigada en las interpretaciones de los campesinos, y una dimensión estructural, correspondiente al contexto global influyente en el contexto local.

\section{CONCLUSIONES}

El conocimiento de las experiencias de las personas involucradas en programas y proyectos que provienen del Estado, es fundamental para poder adentrarse en un contexto particular, dotado de elementos socioculturales que permiten dar a conocer en la práctica como se organizan, significados y símbolos. Por ello el objetivo general es desentrañado transversalmente a lo largo de esta investigación.

Tras lo anterior, se debe comentar que los sistemas de reproducción material manejados por los campesinos son fundamentales al momento de considerar la toma de decisiones cuando se realiza una plantación. Se debe recordar que la economía campesina contempla elementos culturales, sociales, ambientales y políticos, es un todo donde sus partes son sinérgicas. Por lo tanto, si se toma una decisión es en base a esta plataforma de funcionamiento. No obstante la recuperación de campo con fines culturales de fondo fue el gatillante de muchas forestaciones, en el sentido de recuperar esta tierra de la erosión para el ganado (rasgo cultural), fuese crianza de animales en pequeñas cantidades como de ganadería hablando en términos mayores.

De este modo entonces, se ratifica la hipótesis de considerar las forestaciones como determinadas por rasgos culturales, así también económicos ambientales, porque en muchos campesinos el eje es lo ambiental, lo secundario van a ser las bonificaciones. Este punto tiene que ver con los tipos de racionalidad que se establecen en los campesinos, como racionalidad a largo plazo y una racionalidad a corto plazo condicionada por la naturaleza como capital.

Para poder llegar a un conocimiento, como se mencionó al principio, los profesionales forestales y los tomadores de decisiones deben conocer a la gente, sus prácticas y sus costumbres, y no basar sus opiniones en supuestos. La realidad social es mucho más que eso y siempre hay un trasfondo sociocultural que es el productor de las prácticas, por ello la antropología es una disciplina que se percata de este entramado micro social, otorgando un pequeño acercamiento comprensivo para que esas opiniones ya no se basen en supuestos, sino en fundamentos. El conocer los sistemas económicos de los campesinos otorga este acercamiento comprensivo 
a una parte micro de este sistema sociocultural presente mediante opiniones y experiencias de los campesinos. Por tanto, en un trabajo más profundo y con un tiempo más largo se podrá dilucidar la importancia real de las bonificaciones en las economías locales.

El pensamiento local genera el conocimiento de metodologías presente en el funcionamiento rutinario de los campesinos, que no hay que pasar por alto, ya que, pueden ser un factor a favor para el cumplimiento o no de una plantación en cuanto a sus cuidados.

La innovación se consideró un rasgo ambiental, por lo tanto las personas que realizaron forestaciones si son innovadoras, pero hay que contemplar que muchas de ellas preferían lo nativo como una manera de referirse a una sostenibilidad en su racionalidad ambiental.

Por último la composición de las unidades familiares es el eje central para adentrarse en la toma de decisiones en las plantaciones, por lo tanto no se debe considerar sólo la figura de un solo integrante de un grupo o familia, ya que dentro de estos grupos se cumplen funciones sinérgicas, siendo todos los principales protagonistas en las tomas de decisiones, por lo tanto se encuentran preparados para administrar lo que es suyo. De este modo, la comprensión interna de un grupo o familia manifestara sus funciones, divisiones del trabajo, relaciones internas, siendo importante en el progreso de un proyecto o programa. Para ello se debe reconocer la figura de la mujer y los hijos en el mantenimiento, cuidados y en el funcionamiento de las decisiones.

\section{REFERENCIAS}

Bahamondes, M., 2000. La Producción Campesina. Aspectos Sociales, Culturales y Económicos. Ed. Grupo de Investigaciones Agrarias GIA. Documento de Trabajo No 10. Santiago, Chile.

Calva, J., 1988. Los campesinos y su devenir en las sociedades de mercado. Ed. Siglo XXI, México.

Cernea, M., 1996. Primero la gente, variables sociológicas en el desarrollo rural. Fondo de cultura económica/ economía contemporánea.

Comas, D., 1996. Antropología Económica.

Figueroa, A., 1998. En: "Agricultura y Pobreza Rural en América Latina". Lucio Reca y Rubén Echeverría Edit. IFPRI-BID Washington, UEA.

Gascón, A., 2010. Factores de Impacto de Sostenibilidad dentro del Marco del Proyecto Conservación y Manejo Sustentable del Bosque Nativo en la Comuna de Coyhaique, Región de Aysén. Tesis de Magíster en Desarrollo Rural. Universidad Austral de Chile. 
Kroeber, A., 1948. Anthropology: Race, Language, Culture, Psychology, Prehistory. New York: Harcourt, Brace and World.

Murmis, M., 1980. Tipología de Pequeños Productores Campesinos en América Latina. IICA. San José, Costa Rica.

Saavedra, G. 2001. Diagnóstico Área de Desarrollo Coyhaique. Informe Social y Cultural, Proyecto CMSBN. Documento Técnico. CONAF. Coyhaique, Chile.

Schejtman, A., 1982. Economía Campesina: Especificidad, Articulación y Diferenciación. En Economía Campesina y Agricultura Empresarial. Ed. Siglo XXI. México.

Shanner, A., 1982. Farming System Research and Development: Guidelines for Developing Countries. Westview Press, 414 pp. EUA.

Wolf, E., 1982. Los Campesinos. Editorial Labor. Barcelona, España. 150 pp. Título obra original "Peasants". New Jersey. U.S.A. 